\title{
Declining gonorrhoea rates in The Netherlands, 1976-88: consequences for the AIDS epidemic
}

\author{
M J W van de Laar, J Pickering, J A R van den Hoek, G J P van Griensven, R A Coutinho, \\ H P A van de Water
}

\begin{abstract}
The national notification gonorrhoea data are analysed over the period $1976-88$ in conjunction with detailed data from the two STD clinics in Amsterdam in order to get an insight into the underlying reasons for the downward trend of gonorrhoea in The Netherlands. Possible effects of variations in reporting bias, seasonality, resistance against antibiotics, and sexual behaviour on gonorrhoea rates are considered. In 1981 the incidence of gonorrhoea started to decrease, thus preceding the onset of the AIDS epidemic in The Netherlands. Since 1983 the decline in gonorrhoea further accelerated and has been most apparent among homo- and bisexual men, presumably as a result of behavioural changes because of AIDS. There is less evidence for massive (AIDS related) behavioural changes among heterosexuals. The increasing percentage of gonorrhoea patients with recurrent episodes of STDs in Amsterdam may suggest that highly sexually active individuals continue to put themselves at risk of STDs and persist in acquiring and transmitting gonorrhoea.
\end{abstract}

The purpose of this study was to explore the underlying reasons for the trend in the incidence of gonorrhoea in The Netherlands. Variations in the incidence may reflect differences in sexual activity that have occurred in the recent past, possibly as a result of the awareness of the AIDS epidemic.

Gonorrhoea is particularly relevant in this respect because the incidence is known to change rapidly in response to changes in epidemiological factors. ${ }^{1}$ These factors include social aspects such as contact rates among individuals or groups of the population,

TNO Institute of Preventive Health Care, Leiden, The Netherlands

M J W van de Laar, H P A van de Water

University of Georgia, Athens, GA, USA.

J Pickering

Municipal Health Service, Amsterdam, The Netherlands

J A R van den Hoek, G J P van Griensven, R A Coutinho sizes of the affected populations, and intervention and control programmes. They also include clinical aspects such as average infectious periods, for example due to asymptomatic infection in women, virulence of the agent, resistance to antibiotics, and availability and quality of medical care. ${ }^{1}$

Since the first reports on the association of AIDS with a homosexual lifestyle, ${ }^{23}$ the number of reported rectal gonorrhoea cases in homosexual men has decreased in large cities like Denver, Colorado, ${ }^{4} \mathrm{New}$ York, ${ }^{5}$ San Francisco ${ }^{6}$ and, later, in London. ${ }^{7-10}$ The decrease was suggested to be a response to fear of AIDS and a result of a reduction in the number of partners. ${ }^{11} 12$ Furthermore, these suggested changes of sexual behaviour are documented in surveys of sexual behaviour reported by homosexual men in San Francisco, ${ }^{13-16}$ New York, ${ }^{17-18}$ Vancouver, ${ }^{19}$ London $^{20}$ and Amsterdam. ${ }^{21} 22$

In this study two sources of gonorrhoea data are used: the national notification system and the two sexually transmitted disease (STD) clinics in Amsterdam. The notification data are used to study the general trend in gonorrhoea, whereas the more detailed STD clinic data give an insight into possible factors underlying the general trend in gonorrhoea.

\section{Material and methods}

Notification Data

Notification data were collected from the Bureau of the Chief Medical Officer of the Ministry of Health from 1976 to 1988 . Gonorrhoea has been a notifiable disease since 1976. Data are available by date and place of reporting per 4 week-period on gender and age. These data are analysed for The Netherlands and for two major cities, Amsterdam and Rotterdam. These two cities contribute $60 \%$ of the reported national gonorrhoea data. As such, they differ from other cities in The Netherlands and are considered separately here.

The cases are documented by date of reporting rather than by date of diagnosis. As such, variable time-lags between the onset of symptoms and the moment of diagnosis and reporting may distort seasonal fluctuations in the disease incidence. Furthermore, the use of notification data is limited owing to an unknown amount of underreporting. In a recent study ${ }^{23}$ the overall under-notification for gon- 
orrhoea in The Netherlands in 1985 was estimated to be $66 \%$, ranging from $60 \%$ to $95 \%$ in different districts. In a similar study ${ }^{24}$ the under-notification of gonorrhoea in the city of Amsterdam was estimated to be $45 \%$, ranging from $40 \%$ to $90 \%$ among treating physicians. The latter study also showed that the STD clinics of the Municipal Health Service in Amsterdam reported completely and contributed $80 \%$ of the total number of gonorrhoea cases reported in the city.
STD CLINIC DATA

Detailed data were collected from the STD clinics of the Municipal Health Service in Amsterdam over the period 1981-87. Data are available on date of diagnosis, gender, age, town of residence, sexual preference, prostitution, STD history, multiple gonococcal infections and site of infection (urogenital, rectal and oral).

The STD clinics in Amsterdam are estimated to treat about $40 \%$ of all gonorrhoea infections in

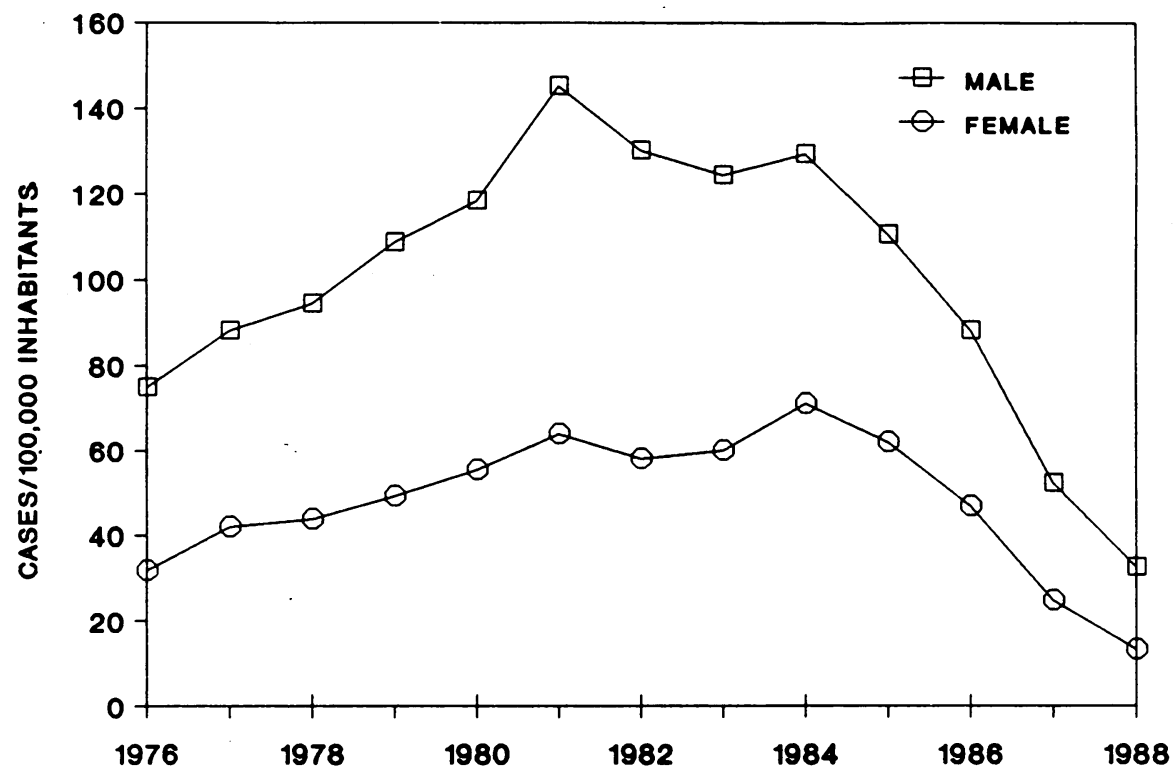

Figure 1 Annual incidence of notified cases of gonorrhoea per 100000 males and females in 1976-88 in (a) The Netherlands, and (b) Amsterdam and Rotterdam. Note the tenfold difference in scale on the $Y$-axis.

FIGURE IA

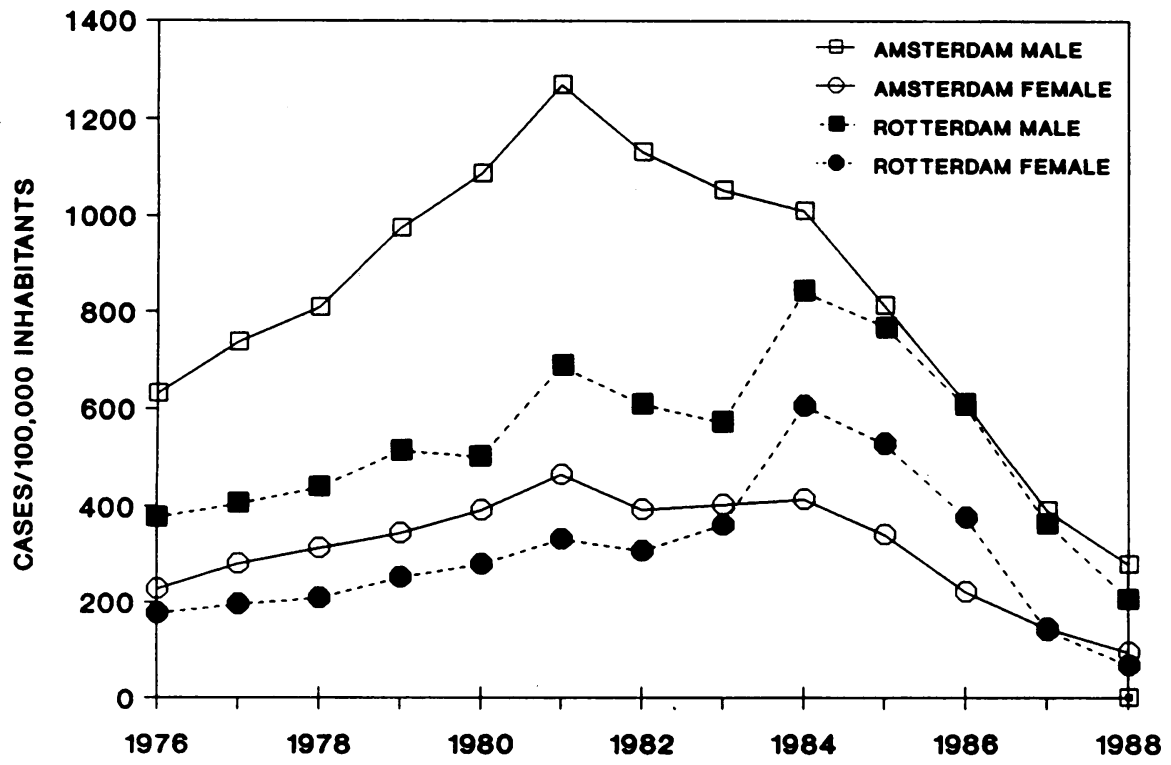

FIGURE 1B 


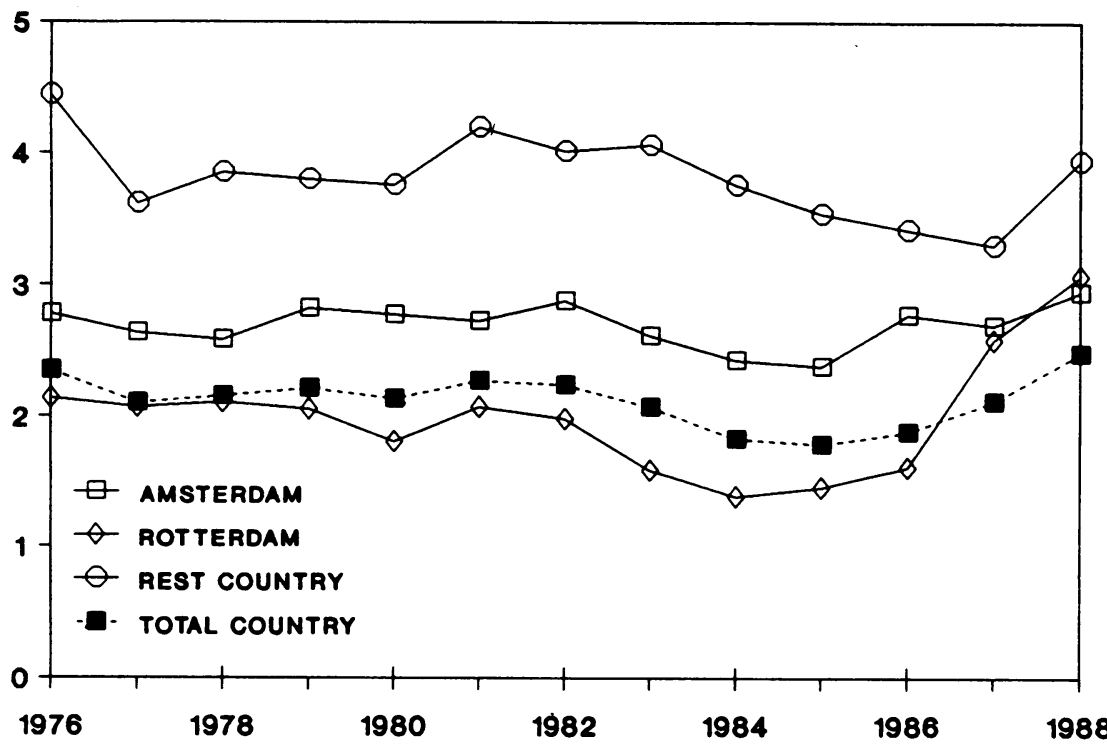

Figure 2 Annual male to female ratio in the incidence (per 100000 inhabitants) of reported gonorrhoea cases in The Netherlands, $1976-88$.

Table Number of gonorrhoea cases by gender, the percentage of those with no previous STD history, prostitution, sexual preference diagnosed in the STD clinics in Amsterdam, 1981-87

\begin{tabular}{|c|c|c|c|c|c|c|}
\hline & \multicolumn{2}{|c|}{$\begin{array}{l}\text { total number } \\
\text { of gonorrhoea } \\
\text { cases }\end{array}$} & \multicolumn{2}{|c|}{$\begin{array}{l}\text { percentage } \\
\text { with no } \\
\text { previous STD }\end{array}$} & \multirow{2}{*}{$\begin{array}{l}\text { percentage } \\
\text { female } \\
\text { prostitutes }\end{array}$} & \multirow{2}{*}{$\begin{array}{l}\text { percentage } \\
\text { homol } \\
\text { bisexual } \\
\text { men }\end{array}$} \\
\hline & male & female & male & female & & \\
\hline $\begin{array}{l}1981 \\
1982 \\
1983 \\
1984 \\
1985 \\
1986 \\
1987\end{array}$ & $\begin{array}{l}3386 \\
3160 \\
2839 \\
2384 \\
2048 \\
1710 \\
1094\end{array}$ & $\begin{array}{r}1253 \\
1059 \\
1044 \\
925 \\
859 \\
666 \\
415\end{array}$ & $\begin{array}{l}44 \cdot 6 \\
44 \cdot 0 \\
35 \cdot 7 \\
32 \cdot 7 \\
34 \cdot 9 \\
37 \cdot 3 \\
32 \cdot 7\end{array}$ & $\begin{array}{l}56 \cdot 2 \\
59 \cdot 2 \\
51 \cdot 0 \\
46 \cdot 8 \\
46 \cdot 8 \\
48 \cdot 2 \\
39 \cdot 2\end{array}$ & $\begin{array}{l}38 \cdot 9 \\
32 \cdot 6 \\
39 \cdot 4 \\
44 \cdot 3 \\
46 \cdot 7 \\
44 \cdot 1 \\
42 \cdot 3\end{array}$ & $\begin{array}{l}32 \cdot 2 \\
36.4 \\
35 \cdot 3 \\
25 \cdot 7 \\
22 \cdot 7 \\
16 \cdot 2 \\
12.6\end{array}$ \\
\hline
\end{tabular}

Amsterdam. ${ }^{24}$ Cure, treatment and counselling are free of charge. It is unknown whether the clientele of the STD clinics is a representative sample of the population with particularly high rate of partner change in Amsterdam, However, the data may give an insight into the patient's background (age, gender, STD history, sexual preference), their infections (such as site of infection) and AIDS risk groups. Patients who entered the clinic more than once per year for treatment of newly acquired infections are considered as new cases on each occasion.

\section{Results}

NOTIFICATION DATA

Figures $1 \mathrm{a}$ and $\mathrm{lb}$ show that nationally and in two

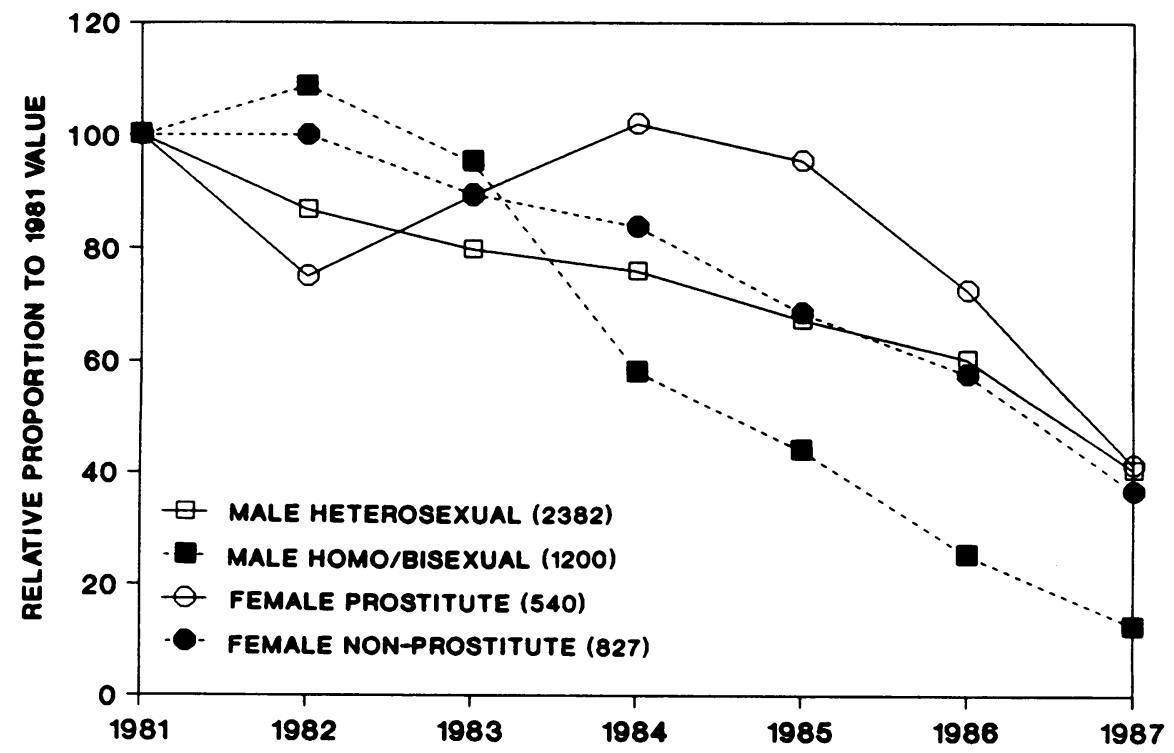

Figure 3 Annual number of gonorrhoea infections diagnosed in two STD clinics in Amsterdam by sexual preference for male cases and prostitution for female cases in 1981-87, relative to the values in 1981 ( set equal to $100 \%$ ). 


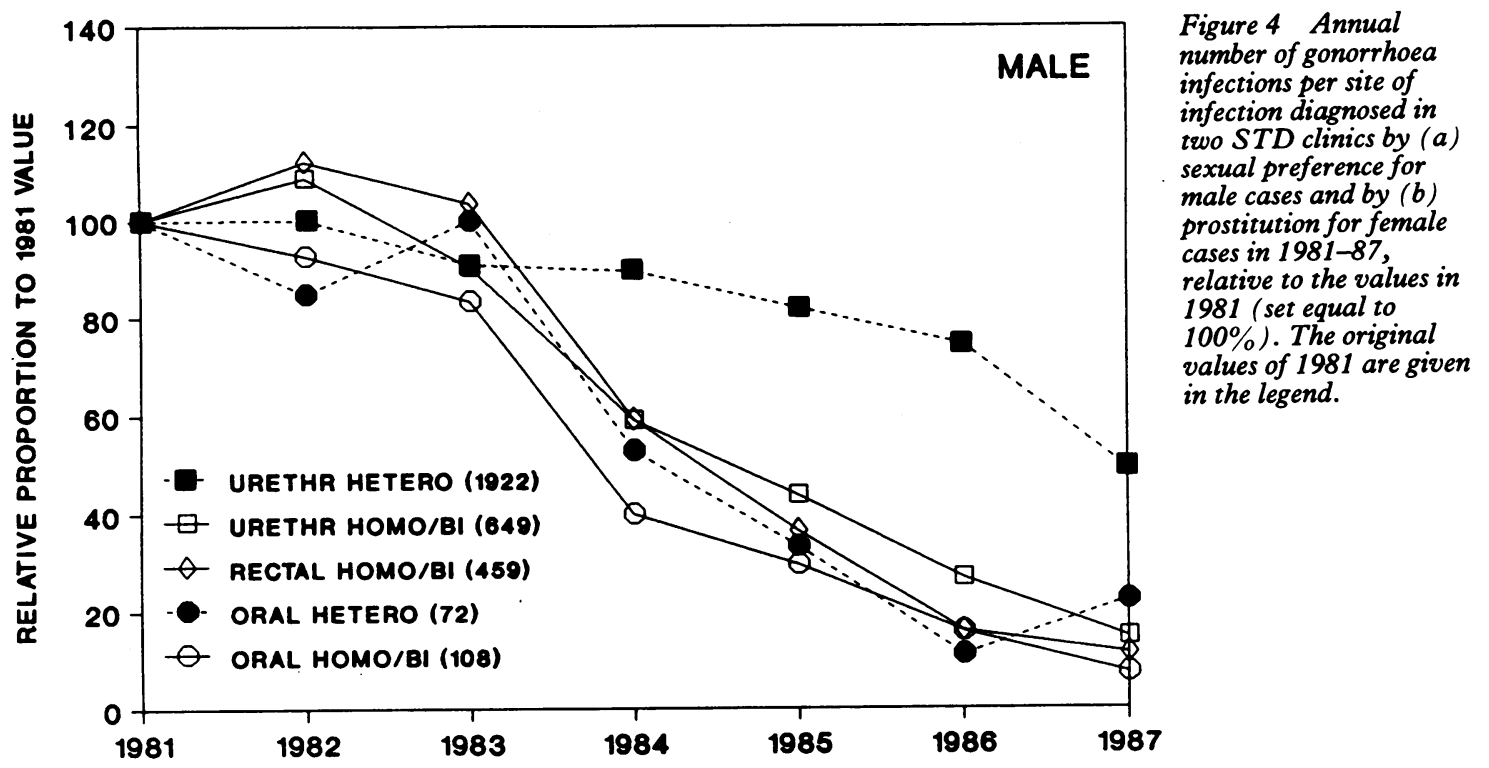

Figure $4 A$

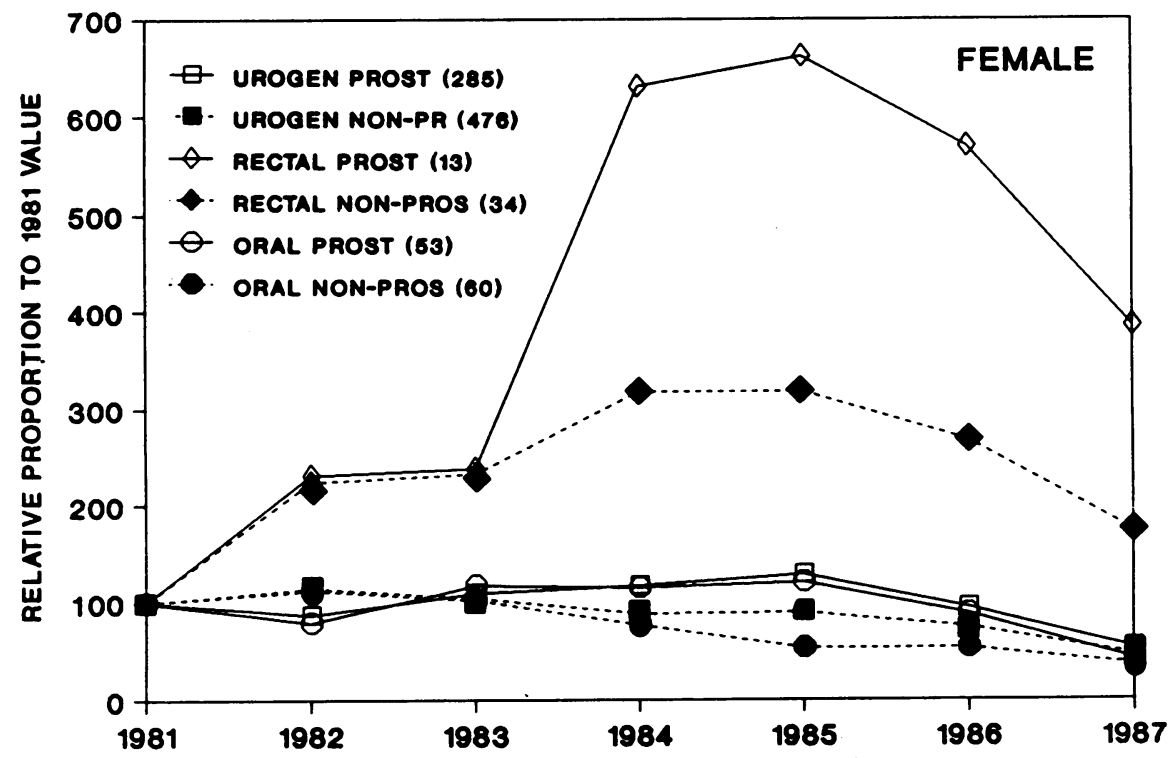

Figure $4 B$

major cities, Amsterdam and Rotterdam, the incidence of gonorrhoea has declined by $78 \%$ between 1981 and 1988. The incidence reached a peak in $\mathbf{1 9 8 1}$ for male cases and in 1984 for female cases and has declined considerably since then. In the past four years the average annual decline was $25-30 \%$. The rate of decline did not differ between the different age groups. The incidence of gonorrhoea by date of reporting shows seasonal fluctuations, being highest from August to October and lowest from March to May.

The incidence of gonorrhoea in Rotterdam was initially half to one third of that in Amsterdam. However, in 1984 the incidence in Rotterdam rose sharply. Nowadays, the trend and the magnitude of the gonorrhoea incidence in these two major cities of The Netherlands are comparable.

Figure 2 shows a fairly constant male to female ratio in the incidence of reported gonorrhoea cases in The Netherlands until 1982. After a drop below 2.0:1 in 1983-86, due to a greater decrease in male cases, the ratio increased again. The ratio in Amsterdam is 1.3 times as high as the ratio for both The Netherlands and Rotterdam, indicating that more male cases 


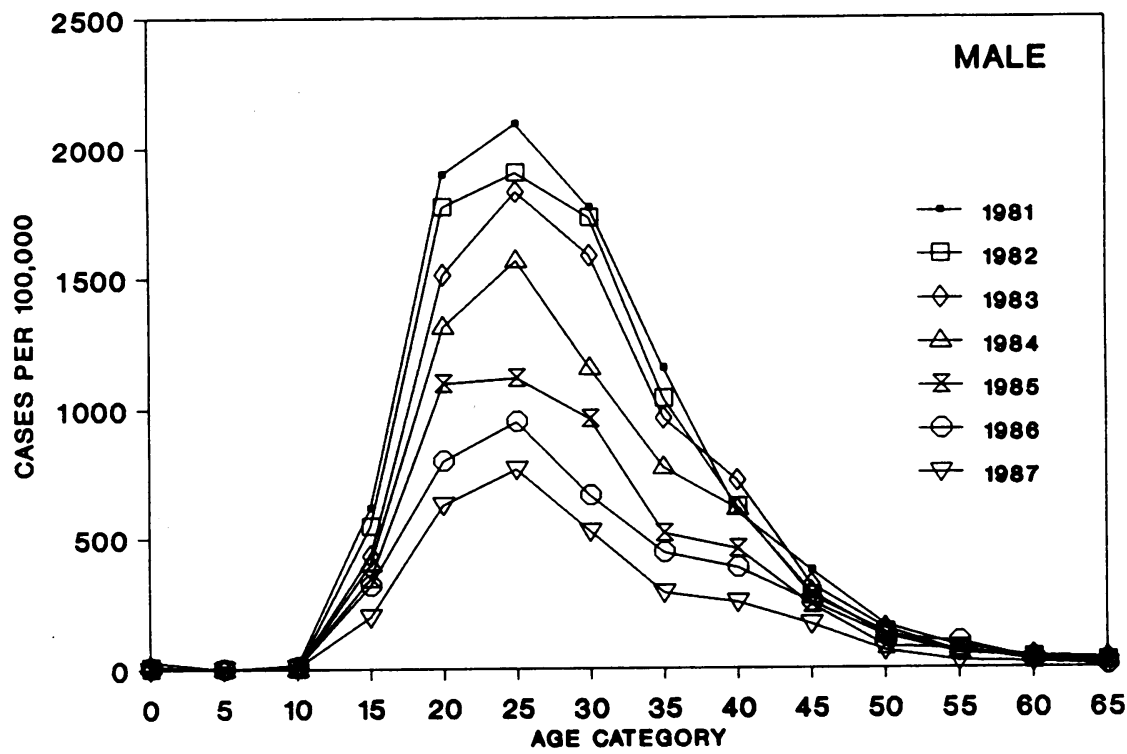

Figure 5 Age-specific incidence of gonorrhoea cases per 100000 inhabitants of Amsterdam for (a) males and (b) females, diagnosed in two STD clinics in Amsterdam in 1981-87.

Figure $5 A$

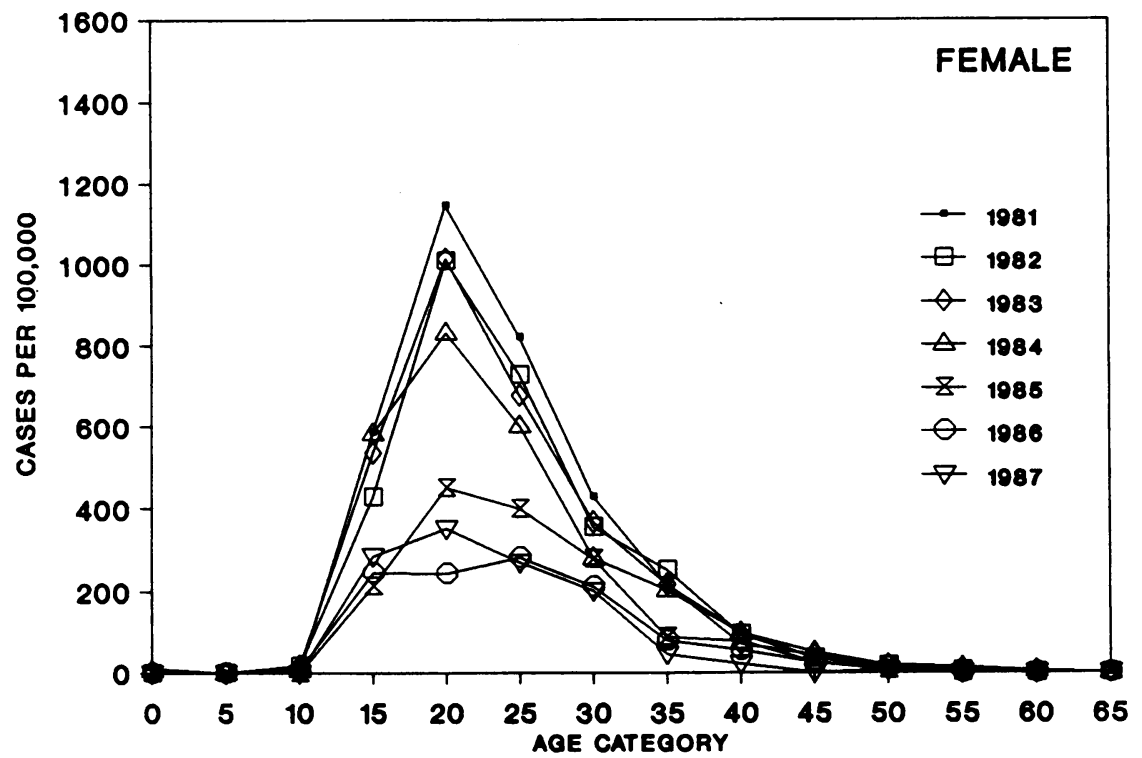

Figure 5B

of gonorrhoea are reported in Amsterdam. Since 1986 the ratio in Rotterdam has increased sharply and is similar to Amsterdam. The ratio in the rest of the country with overall low incidence rates is high.

The average age-pattern in reported gonorrhoea cases in The Netherlands did not change during the period 1977-87, with a peak for males in the age categories 25-29 and 30-34 years. The peak for females has moved from the age category 20-24 years to the categories 25-29 and 30-34 years since 1980 .
STD CLINIC DATA

The total number of new consultations at the STD clinics in Amsterdam remained fairly constant (ca 20 000) during 1981-86, followed by an $18 \%$ decline in 1987. The proportion of gonorrhoea cases has declined continuously from $23.0 \%$ in 1981 to $8.9 \%$ in 1987 . Nearly $85 \%$ of the gonorrhoea patients lives in Amsterdam. The incidence of gonorrhoea in Amsterdam in the period 1981-87 shows a rather stable seasonal pattern with a peak from July to 
October.

The table shows that the number of gonorrhoea cases seen at the STD clinics fell by $67 \%$ between 1981 and 1987. The male-to-female ratio of the gonorrhoea cases is high. The number of individuals who reported never having had an STD (that is, gonorrhoea or syphilis) before, declined from almost half of the individuals in 1981 to one third in 1987. More females than males reported not having experienced an STD before. The percentage of female prostitutes seems to increase slightly. The proportion of homo/bisexual men declined from a quarter to a tenth among the male gonorrhoea patients. The average age (not shown in table) for men (30.3 years) is higher than for women (25.6 years) and has not changed for both sexes over time.

Individuals diagnosed with gonorrhoea may suffer from gonococcal infections at one or more sites, that is, urogenital, rectal and oral. The infections at various sites may reflect the use of different sexual techniques. However, rectal infections in females are not necessarily acquired through anal intercourse but could be acquired from contamination with infected vaginal secretion also.

In the Amsterdam STD clinics, $12 \cdot 1 \%$ of the total number of infections between 1981 and 1987 were from individuals with multiple gonorrhoeal infections. The average number of gonorrhoeal infections in females (range: $1 \cdot 1-1.4$ ) is higher than in males (range: 1.02-1.06) and increases slightly over time, whereas the average number in males remains fairly constant.

Figure 3 presents the trends relative to number of infected sites, rather than individuals. The percentages of infections diagnosed in male prostitutes and homosexual women are low (on average $1.5 \%$ and $0.5 \%$ ) and are not shown. Overall, the annual decline is $17 \%$, with a more apparent decline in homo/ bisexual men since 1983 (87\% decline of the level in 1981) than in heterosexual men, prostitute and nonprostitute females with $56 \%, 59 \%$ and $63 \%$ respectively.

Figure 4a reveals that urethral infections of heterosexual men decreased less than any other male infection. Smoothing the original monthly data with running averages (not shown) reveals a decline of male heterosexual urethral infections in 1982, followed by a rise in 1984 and another drop in 1985 . Rectal infections in homo/bisexual men and oral infections in hetero- and homo/bi-sexual men started to decline in 1983.

Figure $4 \mathrm{~b}$ shows a decline in urogenital and oral infections for both non-prostitutes and prostitutes, but an increase of female rectal infections. Although starting with small absolute numbers and a peak incidence in 1984-85, they eventually reach a level of twice and almost four times the level in 1981.

Figures $5 \mathrm{a}$ and $5 \mathrm{~b}$ show a peak in the age-specific incidence for males in the 25-29 years age group and for females in the 20-24 years age group. The downward trend for both males and females is apparent. The shapes of the curves remain similar, except in flattening of the peak in the curves for females in 1986-87.

\section{Discussion}

In The Netherlands the gonorrhoea incidence rates, both in the national notification data and in the Amsterdam STD clinic data, reveal a continuous decline from 1981 onwards, hereby preceding the onset of the AIDS epidemic. Since 1983 this decline has been further reinforced, to a large extent due to a drop in gonorrhoea in homo/bisexual men, which presumably reflects behavioural changes in this group. Among the heterosexual population there is less evidence for such a strong decline and even an increase of rectal gonorrhoea infections in female prostitutes.

Besides changes in sexual behaviour the disease incidence is affected by other factors which are difficult to quantify. Data, which are indispensable for a correct interpretation, are lacking - that is on the extent to which the STD clientele is representative of the population with high rates of partner change and the general changes in diagnostics and treatment. Therefore the results should be interpreted with caution.

The early decline of gonorrhoea is quite small and may have occurred as a consequence of stabilised reporting patterns and falling incidence rates, due to prior intensified surveillance. As reporting and surveillance by the STD clinics were instituted only in 1976, it seems likely that reporting patterns and STD control activities may not have stabilised for the next several years. There is no evidence that the rising incidence until 1981 was not due to improved case-detection and reporting.

In Amsterdam the amount of under-notification of gonorrhoea in 1985 was estimated to be $45 \%{ }^{24}$ This estimate is based upon a comparison of the number of cases reported per physician with results from interviews among treating physicians in Amsterdam. At present, there is no evidence for change in reporting, despite the probably increased general awareness of STD due to media news coverage on AIDS.

Since 1976 the occurrence of penicillinase producing Neisseria gonorrhoeae (PPNG) has been registered in The Netherlands. In 1981-87 the percentage of PPNG fluctuated between 5-10\% of the notified cases. In Amsterdam, this percentage has increased since $1986^{25}$ and fluctuated between $18-30 \%$ in early $1987 .^{26}$ The PPNG, diagnosed at the same STD clinics, was not only found in prostitutes $(12.9 \%)$ but in heterosexual men $(15.9 \%)$ and non-prostitute females $(17 \cdot 3 \%)$ as well. ${ }^{25}$ The PPNG isolated in 
homo/bisexual men was negligible (1.9\%). The drop in homo/bisexual cases may account for the recent increase of PPNG.

With the exception of homosexuals, the predominance of men in both data sets may be explained by a high exposure to a relatively small group of infectious females, such as prostitutes, and by a high rate of symptomatic disease. The male-to-female ratio is often cited as an index for the efficacy of detection of (asymptomatic) female cases. ${ }^{27}$ However, the high ratio in Amsterdam reflects a large proportion of homosexual men. If these were to be excluded from the calculation of the ratio, a lower figure $(1 \cdot 8-1 \cdot 9)$ is to be found. The rise of the initially lower ratio in Rotterdam to a level comparable with that of Amsterdam is without explanation.

Behavioural changes, such as improved use of condoms or less frequent partner switching, evidently reduce the effective contact rate and affect the disease incidence. The sale of condoms in The Netherlands shows seasonal fluctuations with peaks from May to September. This seasonality corresponds with a high sexual activity during the Summer, as does the disease seasonality (peaking two months later). The overall sale of condoms has increased by $30 \%$ on average only since $1987,,^{28}$ when the national education (Safe Sex) programmes targeted at the general population were started. The number of consultations at the STD clinics in Amsterdam also declined considerably in 1987. Both findings may suggest that behavioural changes among the heterosexual population may have started in 1987.

Educational programmes to convince homosexual men to change their sexual behaviour were organised earlier in Amsterdam, that is, soon after the first AIDS cases were diagnosed in 1982. The drop in male rectal cases indicates that men have reduced anal sex with other men or have used condoms more frequently, a fact which is also observed in the Amsterdam cohort study. 22 The increase of rectal infections in women may be explained by either a change in diagnostic behaviour, through the improvement of the rectal swab sampling technique, or by an increase in anal sex among heterosexuals.

The downward trend is not only observed in gonorrhea infection rates but also in homosexually acquired syphilis ${ }^{29}$ and hepatitis B rates, diagnosed at the same STD clinics in Amsterdam, as well. These infection rates started to decline later than male rectal gonorrhoea, in $1983-4$ and 1985 respectively..$^{30}$ The declines were suggested to be a response to the educational programmes on AIDS. ${ }^{31}$

Similar trends of gonorrhoea have been reported from several western countries, including Canada, Denmark, Finland, Norway, Sweden, the United Kingdom and the USA. ${ }^{27}$ In 1980 the gonorrhoea incidence started to decline sharply in the USA. ${ }^{32}$ Part of this decline was due to an extensive screening programme, which was implemented in 1972 in order to detect asymptomatic female cases. It was estimated that one third of reported female cases (a tenth of all actual gonorrhoea infections in women) was discovered through screening and that the male incidence was hereby made to decrease by $20 \% .^{1}$ In Sweden the reported incidence started to decline in the early $1970 \mathrm{~s}^{273233}$ The falling incidence rate was partly ascribed to the national campaign promoting condoms and a $150 \%$ rise in the sale of condoms.

In conclusion, the gonorrhoea population in Amsterdam presumably is changing over time with respect to STD history and sexual preference. In 1987 almost twice as many gonorrhoea patients report to have experienced a prior STD compared with 1981. A history of past STD infection is often indicative of a high rate of partner change. The importance of these core groups in maintaining a STD infection within the general population has been shown by Hethcote and Yorke ${ }^{1}$ and by Rothenberg $^{34}$ with respect to gonorrhoea and by Anderson and $\mathrm{May}^{35}{ }^{36}$ with respect to HIV. The increasing percentage of individuals with a STD history possibly indicates that repeat infection is increasing among gonorrhoea patients and suggests that there is a group of highly sexually active individuals who continue to practise higher risk behaviours and put themselves at risk of STDs. The conclusion from this might be that the change in behaviour in this population may be less marked than in sectors of the population who have not had a previous STD. The residual proportion of the homo/bisexual men even shows a doubling in those with repeat infection since 1981. The decreasing percentage of individuals with no STD history indicates that they either prevent an infection or seek cure and treatment elsewhere. However, this point needs to be clarified in order to determine the nature of behavioural changes and help to assess the potential for the spread of HIV.

We thank Wim van Nooten for his support during this study and Louis Ouwerling and Toine Rijsdijk for their assistance in data-management. We also thank Professor Jan P Vandenbroucke and Professor Roy $M$ Anderson FRS for their helpful comments in preparing this paper.

Address for correspondence: $\mathrm{M} \mathrm{J} \mathrm{W}$ van de Laar, TNO Institute of Preventive Health Care, PO Box 124, 2300 AC Leiden, The Netherlands

1 Hethcote HW, Yorke JA. Gonorrhoea transmission dynamics and control. Lecture notes in biomathematics, No 56. Heidelberg: Springer-Verlag 1984.

2 Friedman-Kien A, Laubenstain L, Marmor M, et al. Kaposi's sarcoma and Pneumocystis among homosexual men-New 
York City and California. MMWR 1981;30:25:305-8.

3 Fannin S, Gottlieb MS, Weisman JD, et al. A cluster of Kaposi's sarcoma and Pneumocystis carinii pneumonia among homosexual male residents of Los Angeles and Orange counties, California. MMWR 1982;31:23:305-7.

4 Judson FN. Fear of AIDS and gonorrhoea rates in homosexual men. Lancet 1983;i:159-60.

5 Schultz S, Friedman S, Kristal A, Sencer DJ. Declining rates of rectal and pharyngeal gonorrhoea among males-New York City. MMWR 1984;33:21:295-7.

6 Pickering J, Wiley JA, Padian NS, Lieb LE, Echenberg DE, Walker $J$. Modeling the incidence of acquired immunodeficiency syndrome (AIDS) in San Francisco, Los Angeles, and New York. Mathematical Modelling 1986;7:661-88.

7 Weller JVD, Hindley DJ, Adler MW, Meldrum JT. Gonorrhoea in homosexual men and media coverage of the acquired immune deficiency syndrome in London, 1982-3. Br Med J 1984;289:1041.

8 Gellan MCA, Ison CA. Declining incidence of gonorrhoea in London: a response to fear of AIDS? Lancet 1986;i:920.

9 Carne CS, Weller JVD, Johnson AM, et al. Prevalence of antibodies to human immunodeficiency virus, gonorrhoea rates, and changed sexual behaviour in honosexual men in London. Lancet 1987;i:119-21.

10 Lawrence AG, Singaratnam AE. Changes in sexual behaviour and incidence of gonorrhoea. Lancet 1987;1:982-3.

11 Golubjatnikov R, Pfister J, Tillotson T. Homosexual promiscuity and the fear of AIDS. Lancet 1983;1:681.

12 Schechter MT, Jeffries E, Constance P, et al. Changes in sexual behaviour and fear of AIDS. Lancet 1984;i:1293.

13 McKusick L, Horstman W, Coates T. AIDS and sexual behavior reported by gay men in San Francisco. Am J Public Health 1985;75:493-6.

14 Werdegar D, O'Malley P, Bodecker T, Hessol N, Echenberg D. Self-reported changes in sexual behaviors among homosexual and bisexual men from the San Francisco City Clinic Cohort. MMWR 1987;36:12:187-9.

15 Winkelstein W, Lyman DM, Padian N, et al. Sexual practices and risk of infection by the Human Immunodeficiency Virus. The San Francisco men's Health Study. JAMA 1987;257:321-5.

16 Winkelstein W, Wiley JA, Padian NS, et al. The San Francisco Men's Health Study. Continued decline in HIV seroconversion rates among homo/bisexual men. Am J Public Health 1988;78:1472-4.

17 Martin J. The impact of AIDS on gay male sexual behaviour patterns in New York City. Am J Public Health 1987;77: 578-81.

18 Martin JL, Garcia MA, Beatrice ST. Sexual behaviour changes and HIV antibody in a cohort of New York City gay men. Am J Public Health 1989;79:501-3.

19 Schechter MT, Craib KJP, Willoughby B, et al. Patterns of sexual behavior and condom use in a cohort of homosexual men. Am J Public Health 1988;78:1535-8.
20 Evans BA, McLean KA, Dawson SG, et al. Trends in sexual behaviour and risk factors for HIV infection among homosexual men, 1984-7. Br Med J 1989;298:215-8.

21 Van Griensven GJP, Vroome EMM, de, Tielmen RAP, et al. Impact of HIV antibody testing on changes in sexual behaviour among homosexual men in The Netherlands. $\mathbf{A m} \mathrm{J}$ Public Health 1988;78:1575-7.

22 Van Griensven GJP, Vroome EMM de, Goudsmit J, Coutinho RA. Changes in sexual behaviour and the fall in incidence of HIV infection among homosexual men. $\mathrm{Br}$ Med $J$ 1989;298:218-21.

23 Miltenburg HMThM, Paalman MEM, Reus JThNM. Gonorroe in Nederland. Utrecht, SOA-Stichting 1988.

24 Van de Laar MJW, Van de Water HPA. Gonorroe en syfilis in de regio Amsterdam. Leiden, NIPG-TNO report nr. 87016, 1987.

25 Geslachtsziektenbestrijding GG en GD Amsterdam. Jaarverslag 1987. Amsterdam 1989.

26 Van Everdingen JJE. Sexueel overdraagbare aandoeningen. In: Grobbee DE \& Hofman A: eds. Epidemiologie van ziekten in Nederland. Utrecht, Bunge 1989:127-36.

27 WHO. Neisseria gonorrhoeae and gonococcal infections. Technical Report Series 616, 1978.

28 SOA Stichting. Jaarverslag 1987. Utrecht 1988.

29 Fennema JSA, Van den Hoek JAR, Rijsdijk AJ, Van der Linden MMD, Coutinho RA. Het voorkomen van seksueel overdraagbare aandoeningen bij bezoekkers van twee geslachtsziektenpoliklinieken in Amsterdam, 1981-7. Ned Tijdschr Geneeskd 1989;133:886-90.

30 Van Griensven GJP, Van den Hoek JAR, Leentvaar A, Coutinho RA. Surrogate markers for HIV incidence among homosexual men. J Inject Dis 1989;159:1157-8.

31 Coutinho RA, Schoonhoven JF, Van den Hoek JAR, Emsbroek JA. Influence of special surveillance programmes and AIDS on the declining incidence of syphilis in Amsterdam. Genitourin Med 1987;63:210-3.

32 Handsfield H. Gonorrhoea and Uncomplicated Gonococcal Infection. In: Sexually Transmitted Diseases, Holmes KK, Mardh P, Sparling PF, Wiesner PJ, eds. McGraw-Hill, 1984.

33 Danielson D. Gonorrhoea. In: Oriel JD \& Waugh $\mathbf{M}$, eds. Proceedings of Anglo-Scandinavian conference on sexually transmitted diseases. London, Royal Society of Medicine Services, 1988 .

34 Rothenberg RB. The geography of gonorrhoea. Empirical demonstration of core group transmission. Am J Epidemiol 1983;117:688-94.

35 May RM, Anderson RM. Transmission dynamics of HIV infection. Nature 1987;326:137-42.

36 Anderson RM, May RM. Epidemiological parameters of HIV transmission. Nature 1988;333:514-9.

Accepted for publication 20 November 1989 